\title{
Economic benefits of immigration for natives: the effects of immigrants through the school system
}

\author{
Masatoshi Jinno $^{1}$ (D) Masaya Yasuoka ${ }^{2}$
}

Received: 25 April 2021 / Accepted: 31 January 2022 / Published online: 3 March 2022

(c) The Author(s) 2022

\begin{abstract}
Immigration can have indirect negative effects, such as the additional burden of providing education to immigrant children who may need more support than native children to master the culture, customs, and language of the host country. This also leads to a transition of labor from the consumption sector to the education sector and a change in the number of children through the costs of education. Thus, using an overlapping generation model, we examine the effects of immigration on the welfare of the native population with the burden of providing schooling to native and immigrant children with endogenous fertility rates and endogenous unemployment rates. The results indicate that immigration may improve the welfare of the native population when the number of educators required for immigrant children is sufficiently low. Moreover, whether immigration improves the welfare of the native population depends not on the productivity of immigrants but on the increment in the number of educators caused by immigration.
\end{abstract}

Keywords Endogenous fertility $\cdot$ Unemployment $\cdot$ Immigrants $\cdot$ Burden of schooling

JEL Classification J61 $\cdot$ J65 $\cdot$ H75

\section{Introduction}

As of 2019, the number of people living outside their country of origin reached an estimated 272 million, or approximately $3.5 \%$ of the world's population (International Organization for Migration 2019). The share of international migrants in 2019

Masatoshi Jinno

jimasato@nanzan-u.ac.jp

1 Department of Economics, Nanzan University, 18 Yamazato-cho, Showa-ku, Nagoya, Aichi 466-8673, Japan

2 School of Economics, Kwansei Gakuin University, 1-155 Uegahara Ichiban-Cho, Nishinomiya, Hyogo 662-8501, Japan 
was the highest in Oceania, North America, and Europe, with 21, 16, and $11 \%$ of the total population, respectively (United Nations Department of Economic and Social Affairs, Population Division 2019). According to the report "Statistics on Foreign Nationals Residing in Japan" by Japan's Ministry of Justice (2020), the number of foreign residents in Japan rose to 2,829,416 individuals as of the end of June 2019, from a mere 850,612 individuals at the end of December 1985, a $232.6 \%$ increase. These data imply that developed countries, especially Japan, with its declining birthrate and rapidly aging society, have accepted an increasing number of immigrants.

As Card (2001), Borjas (2003), and Dustmann et al. (2017) show, immigration has negative effects on the host country's employment rate. Kemnitz (2003) also models the complementary relationship between unskilled and skilled labor, finding that admitting unskilled immigrants raises the unemployment rate. However, while Japan has accepted an increasing number of immigrants, the average annual unemployment rate in Japan in 2019 was $2.2 \%$, which is lower than the $2.7 \%$ unemployment rate in 1985, implying that immigrants might have no effect on the native unemployment rate. ${ }^{1}$ Moreover, recent studies (Basten and Siegenthaler 2019; Esposito et al. 2020; Furlanetto and Robstad 2019) show positive effects of immigration on native citizen employment rates. Hence, immigration might not only revitalize the employment rate of the host country but also improve employment opportunities. These positive results, including some from a Japanese case, cannot be explained by the standard model described in Edo (2019), which is a framework for the effects of immigration in host countries based on the intensity of the capital-labor ratio from short- and long-term perspectives. ${ }^{2}$

Thus, we should consider additional structural factors that might improve employment opportunities for the native population. In this study, we explore the structural indirect effects of accepting immigrants from the perspective of education.

The educational perspective includes opportunities for the native population to teach immigrants language, culture, and the like, which are essential for them to work and live in the host country. While such educational opportunities improve the employment rate, they also burden the native population with financing workers' wages as educators. These reinforced processes are underway, especially in Japan,

\footnotetext{
1 These data come from the "Labor Force Survey" released by the Ministry of Education, Culture, Sports, Science and Technology in Japan, Statistics Bureau Home Page/Labour Force Survey/Historical data (accessed 4 August 2021).

2 Admitting immigrants primarily results in an increase in the labor force in the host countries, thus decreasing the level of physical capital and productivity per worker. Additionally, the decrease in the wage rate due to immigration can result in some native residents exiting the labor force. Thus, the shortterm effect of immigration from the capital-labor ratio perspective is a decrease in the wage rate and an increase in the unemployment rate of the native population. However, these effects increase the return to the complementary factor, capital, which attracts foreign capital inflow and leads individuals to save more domestically. The accumulation of capital following the instantaneous change in the capital-labor ratio improves labor productivity, thereby increasing both the wage rate and demand. This is the longterm effect of immigration. Moreover, in a perfect capital market, there may be no lag in the response of capital to the changes caused by immigration, and the capital-labor ratio and the wage either remain the same or there is a minuscule negative effect (e.g., Breunig et al. 2017; Dustmann et al. 2005).
} 
which is experiencing a declining fertility rate and a sharp increase in the proportion of older adults.

The revised law-namely, the "Act on Amending the Immigration Control and Refugee Recognition Act and the Ministry of Justice Establishment Law"-was passed on December 8, 2018. This law establishes the new residential statuses of Special Skilled Worker (1) and Special Skilled Worker (2) in addition to the existing status of Trainees and Technical Interns, as well as the Immigration Services Agency. ${ }^{3}$ To promote the acceptance of immigrants, acts such as the "Comprehensive Measures for Acceptance and Coexistence of Foreign Nationals" (CMA) were promulgated and came into force in 2019. The acceptance of immigrants with the status of Special Skilled Worker (1) has not proceeded as smoothly as scheduled, but the number of immigrants with this status gradually increased from 3,632 in 2019 to 42,653 at the end of August 2020. ${ }^{4}$ An increased number of immigrants also implies an increase in the burden of education. The total budget related to the CMA was approximately 61 billion yen in 2018, 193.4 billion yen in 2019, and 350.2 billion yen in 2020. After the Immigration Control Act was revised in 2018, Japan finally began to enhance educational support for the children of foreign residents, which could be a burden for the native population. However, this might not be preferable to the native population, and policymakers should also consider the educational costs of immigration.

Kojima (2016), however, reports that approximately $10 \%$ of elementary and junior high school students do not attend school because of the difficulty children and their parents have with learning Japanese. ${ }^{5}$ Furthermore, $92.9 \%$ of immigrant junior high school students did not attend high school, though the average dropout rate of junior high school students in Japan was only $4.2 \%$ in $2020 .{ }^{6}$ Kojima (2016) also explains how important it is for the education sector to improve language acquisition support in Japan. This implies that the public sector should increase education support to help the children of immigrants continue schooling and assimilate, such

\footnotetext{
3 Specified Skilled Worker (1) and (2) are resident statuses created to give foreign nationals more opportunities to work in Japan. The Technical Intern Training Program defines trainees and interns as those who have come from developing countries to Japan to learn manufacturing technology, quality control, and the like. Overall, they are treated as useful low-wage workers in small- and medium-sized enterprises. Thus, there is a simple definitional difference between Specified Skilled Worker (1) and (2) and trainees and interns. The former are workers, and the latter are interns.

4 There are four other types of foreign residents in addition to Special Skilled Workers and Trainees and Technical Interns: (1) residents based on status (approximately 532,000 people in 2019), (2) residents for work purposes (approximately 329,000 people), (3) designated activities (approximately 41,000 people), and (4) activities other than those permitted by the status of residence previously granted (approximately 373,000 people). Thus, the number of immigrants in Japan increased to 1,659,000 people in 2019, from only 486,398 people in 2008. See the Immigration Services Agency of Japan (http://www.moj.go.jp/isa/ policies/coexistance/nyuukokukanri01_00140.html) (accessed 16 March 2021).

5 The percentage value is based on children whose location could be confirmed. The number of children of immigrants who could not be contacted was more than twice the number of those who were confirmed.

6 The average number of junior high school students in Japan according to Deputy Director-General, Elementary and Secondary Education Bureau (2021) https://www.mext.go.jp/a_menu/shotou/kaikaku/ main8_a2.htm (accessed 16 March 2021).
} 
as by increasing the number of educators supporting these children. The Ministry of Education, Culture, Sports, Science and Technology decided to increase the minimum number of teachers providing support as Japanese language teaching assistants to one teacher per 18 children in 2026 (Nikkei 2020). This suggests a shift in native workers from the production sector to the education sector-a transition that could pose an additional financial burden, which might decrease the number of children the native population will bear. Thus, the effects of immigration should be considered in the endogenous fertility rate model.

Regarding the effects of immigration on education, Speciale (2012), for example, estimates that increases in the immigrant population have a small negative effect on public education expenditures in the EU-15 countries. In contrast, Mavisakalyan (2011) employs a gravity model and demonstrates that an increase in the proportion of immigrants raises private school enrollment across countries, thereby leading to a decrease in the share of public education spending. Other studies indicate a positive net effect of immigration on the high school completion and college enrollment of natives in the USA (Hunt 2017; Jackson 2015). These studies examine the effects of immigration from an educational perspective but do not consider the structural labor transition by examining the education sector through a theoretical lens. Albornoz et al. (2018a, b, c) consider educational structures in which student performance interacts with parental and teacher investments and school system resources and find a positive relationship between parental immigration costs and children's academic achievements. They do not, however, consider the burden of schooling, such as financing the wages of educators, as well as the decrease in the labor force caused by an additional increase in the number of educators as a result of immigration.

After incorporating the abovementioned features into the model, we analyze whether immigration improves the welfare of the native population. Considering the educational perspective of immigration highlights another unclear aspect of immigration, thereby contributing to the economic dimension of global immigration debates.

The rest of this paper is organized as follows: Sects. 2 and 3 present the model and welfare analysis, Sect. 4 presents the discussion of the findings, and Sect. 5 concludes the paper.

\section{The model}

We apply an overlapping generations model, in which individuals live for three periods: childhood, the working period, and retirement. Children require educators. Individuals in the working period are endowed with one unit of labor that is inelastically supplied to the consumption or education sector if they are employed. If unemployed, individuals receive unemployment benefits. According to expected income, individuals determine the amount of consumption, savings, and the number of children and subsequently retire in old age. To investigate the effects of immigration through the education system on the social welfare of the native population, we do not consider the pension system. 
The term immigrant refers only to those who are admitted as non-citizens in the initial period. For simplicity, however, we assume that the children of immigrants have the same productivity as natives owing to the educational support provided by an additional number of educators. Thus, we treat them as we treat natives in the next period. In this model, we analyze the effects of admitting only one-time immigrants.

\subsection{Admitting immigrants in the working period}

In period zero, working immigrants, the $\lambda$ rate of native working people, enter the country without capital. ${ }^{7}$

$$
N_{t}^{I M}=\lambda N_{t}^{N}
$$

where $N_{t}^{I M}$ is the number of immigrants in period $t$, and $N_{t}^{N}$ is the number of native working people in period $t$. Superscripts $I M$ and $N$ denote immigrants and native residents, respectively. Thus, the population of the $t^{\text {th }}$ generation, including immigrants, becomes $N_{t}^{T}=N_{t}^{N}+N_{t}^{I M}=(1+\lambda) N_{t}^{N}$. P is the relative productivity of immigrants compared to that of natives; we assume it to be less than one. ${ }^{8}$

\subsection{Child-rearing and education}

Children of the native population need a certain number of educators for rearing and education, $h^{N}$, though the children of immigrants need additional educators. Thus, the number of educators immigrants require, $h^{I M}$, is higher than $h^{N}$. The relationship between the number of educators per native and immigrant child is

$$
h^{N}<h^{I M}=q h^{N},
$$

where $q>1$. The total number of educators native and immigrant children need in period $t, H_{t}$, becomes

$$
H_{t}=h^{N} n_{t}^{N}+h^{I M} n_{t}^{I M}
$$

\footnotetext{
${ }^{7}$ Similar to Razin and Sadka (2000), Kemnitz (2003), and Jinno (2011, 2013), we consider the distribution in skill level. Muysken et al. (2015) also show that medium-skill immigration decreases low-skilled unemployment under a flexible regime in a general equilibrium framework. However, we do not consider this point to retain our focus on the burden of schooling and for simplicity in calculation.

8 According to the "Basic Survey on Wage Structure" by the Ministry of Health, Labour and Welfare (2021), the sum of the actual number of scheduled hours worked and the actual amount of overtime worked for all academic backgrounds for natives and immigrants are 2,100 and 2,172 h per year, respectively. The total contractual cash earnings multiplied by 12 and the annual special earnings are $4,872.90$ thousand yen and 3,077.60 thousand yen per year for natives and immigrants, respectively. The productivity of natives and immigrants - that is, the rate of earnings to working hours-is 2.32 and 1.41 , respectively. Thus, the relative productivity of immigrants to natives in Japan is 0.61 , which is less than one. $\mathrm{P}$ is the relative productivity of immigrants compared to that of native residents and is based on earnings rather than working hours.
} 
where $n_{t}^{N}\left(n_{t}^{I M}\right)$ is the number of children per native (immigrant).

With a greater number of educators, the children of immigrants could be expected to fully exert their abilities, similar to natives, when they are adults. However, this is a very strong assumption. Results from the 2018 Programme for International Assessment (PISA) (Organisation for Economic Co-operation and Development [OECD] 2019) showed that immigrant children scored lower than the children of natives, even though they received more additional support from educators compared to native children in some host countries. Thus, this strong assumption of equivalent outcomes does not seem to be supported as some immigrant children's abilities may remain below those of native children, even if they receive additional educational support. In such cases, assimilation costs need to be explicitly considered, similar to Jinno $(2011,2013)$, who extended the approaches of Razin and Sadka (1999) by explicitly considering the effects of assimilation costs. According to Jinno $(2011,2013)$, the additional burden of assimilation into the host country may reduce the possibility of improving native welfare in current models, which remains to be explicitly addressed. ${ }^{9}$

For simplicity, immigrant children become native during period $t+1$. Thus, the transition of the generation's population, including immigrants, becomes

$$
N_{t+1}^{N}=n_{t}^{N} N_{t}^{N}+n_{t}^{I M} N_{t}^{I M}
$$

which implies that the children of immigrants become perfectly assimilated in the host country and that there are no effects of being a child of immigrants in the host country without additional educational support.

\subsection{Labor market}

There are two labor markets: the consumption and education sectors. For simplicity, native and immigrant workers in the consumption sector face a common unemployment rate:

$$
u_{t}^{E}=\frac{U n_{t}^{N}}{E_{t}^{N}}=\frac{U n_{t}^{I M}}{E_{t}^{I M}}
$$

where $u_{t}^{E}$ is the ratio of unemployed workers to employed workers, $U n_{t}^{X}$ is the number of unemployed workers attributed to $X \in(N$ or IM $)$, and $E_{t}^{X}$ is the number of employed workers attributed to $X$. Superscript $E$ indicates that the variable is common among the native and immigrant groups. The ratio of the employed to the population of the $t$ th generation attributed to $X$ is

\footnotetext{
${ }_{9}$ According to the 2018 PISA results (OECD 2019) regarding linguistic differences between first- and second-generation immigrant students, compared to first-generation immigrants, fewer second-generation immigrants speak a language at home that is different from the language of instruction. These findings provide some limited empirical evidence showing that the children of immigrants become assimilated into the host country.
} 


$$
\epsilon_{t}^{X}=\frac{E_{t}^{X}}{N_{t}^{X}}
$$

Using Eqs. (1), (5), and (6), the number of unemployed native (immigrant) workers becomes

$$
\begin{gathered}
U n_{t}^{N}=u_{t}^{E} \epsilon_{t}^{N} N_{t}^{N}, \\
\begin{aligned}
U n_{t}^{I M} & =u_{t}^{E} \epsilon_{t}^{I M} N_{t}^{I M} \\
& =u_{t}^{E} \epsilon_{t}^{I M} \lambda N_{t}^{N} .
\end{aligned}
\end{gathered}
$$

In the education sector, only the native language is employed because individuals must educate both immigrant and native children to learn the host country's language, culture, and on the like. Labor in the education sector does not face unemployment. Natives can be employed or unemployed in the consumption sector and can be employed in the education sector. The constitution of native labor becomes

$$
N_{t}^{N}=E_{t}^{N}+U n_{t}^{N}+H_{t}^{N} .
$$

Using Eqs. (6-8), the number of educators in period $t$ is

$$
H_{t}^{N}=\left(1-\left(1-u_{t}^{E}\right) \epsilon_{t}^{N}\right) N_{t}^{N} .
$$

Substituting Eqs. (7) to (9) into Eq. (6), we obtain the employment rate in the consumption sector for the native (the immigrant) in period $t$ :

$$
\begin{gathered}
\epsilon_{t}^{N}=\frac{1-\left(n_{t}^{N}+\lambda q n_{t}^{I M}\right) h^{N}}{1+u_{t}^{E}}, \\
\epsilon_{t}^{I M}=\frac{1}{1+u_{t}^{E}} .
\end{gathered}
$$

Using Eq. (10), the relationship between the native and immigrant populations with regard to the employment rate in the consumption sector is

$$
\epsilon_{t}^{I M}=\frac{1}{1-\left(n_{t}^{N}+\lambda q n_{t}^{I M}\right) h^{N}} \epsilon_{t}^{N} .
$$

In contrast, while the productivity of natives is one, that of immigrants is $\mathrm{P}$. Considering the productivities of the native and the immigrant, the labor supplied by the native and immigrant populations in the consumption sector becomes $L_{t}^{N}=E_{t}^{N}=\epsilon_{t}^{N} N_{t}^{N}$ and $L_{t}^{I M}=\mathrm{P} E_{t}^{I M}=\mathrm{P} \epsilon_{t}^{I M} N_{t}^{I M}=\lambda \mathrm{P} \epsilon_{t}^{I M} N_{t}^{N}$, respectively. Thus, the total labor force supplied by the native and immigrant populations, $L_{t}^{L}=L_{t}^{N}+L_{t}^{I M}$, is

$$
L_{t}^{L}=\left(1+\frac{\lambda \mathbf{P}}{1-\left(n_{t}^{N}+\lambda q n_{t}^{I M}\right) h^{N}}\right) \epsilon_{t}^{N} N_{t}^{N},
$$


which considers unemployed workers. If all workers are employed, then the total labor force supplied by native and immigrant workers becomes

$$
L_{t}^{F}=\left(1+u_{t}^{E}\right)\left(1+\frac{\lambda \mathbf{P}}{1-\left(n_{t}^{N}+\lambda q n_{t}^{I M}\right) h^{N}}\right) \epsilon_{t}^{N} N_{t}^{N} .
$$

\subsection{Firms in the consumption sector}

The production function is $Y_{t}=\left(K_{t}^{T}\right)^{\delta}\left(L_{t}^{T}\right)^{(1-\delta)}$, where $\delta \in(0,1) . Y_{t}, K_{t}$, and $L_{t}$ denote the output produced, capital, and labor, respectively. The variables with superscript $T$ are the total number of variables.

We assume that the wage in the consumption sector at period $t, w_{t}^{L}$, is

$$
w_{t}^{L}=\mu w_{t}^{F}, \mu>1,
$$

where $\mu$ is the markup rate, which leads to unemployment, and $w_{t}^{F}$ is the wage rate when all workers in the consumption sector are fully employed. ${ }^{1}$

We assume that all capital at the end of each period depreciates in one period. According to profit maximization theory, we have

$$
\begin{gathered}
w_{t}^{L}=(1-\delta)\left(k_{t}^{N}\right)^{\delta}\left(\frac{L_{t}^{T}}{N_{t}^{N}}\right)^{-\delta}, \\
1+r_{t}^{L}=\delta\left(k_{t}^{N}\right)^{\delta-1}\left(\frac{L_{t}^{T}}{N_{t}^{N}}\right)^{1-\delta},
\end{gathered}
$$

where $k_{t}^{N} \equiv \frac{K_{t}^{T}}{N_{t}^{N}}$ when there are unemployed workers in the consumption sector. While the native supply is one unit of time, the immigrant can only supply $\mathrm{P}$ units of time. Thus, the income of the immigrant becomes $\mathrm{P} w_{t}^{m}$.

However, we also have solutions according to profit maximization when all workers in the consumption sector are employed:

$$
w_{t}^{F}=(1-\delta)\left(k_{t}^{N}\right)^{\delta}\left(\frac{L_{t}^{F}}{N_{t}^{T}}\right)^{-\delta}
$$

\footnotetext{
${ }^{10}$ We should consider the theoretical foundation of why the wage rate is effectively set over that under full employment. In this study, we consider it important to focus on the relationship between the effects of immigration by considering educational burdens and social welfare. Thus, we simplify the model as much as possible such that we do not address the theoretical foundation, which is also a pertinent issue that will remain for future research.
} 


$$
1+r_{t}^{F}=\delta\left(k_{t}^{N}\right)^{\delta-1}\left(\frac{L_{t}^{F}}{N_{t}^{T}}\right)^{1-\delta}
$$

Using Eqs. (14-16), the endogenously calculated common ratio of unemployed workers to employed workers in the consumption sector becomes constant: ${ }^{11}$

$$
u^{E^{*}=\mu^{\frac{1}{\delta}}-1}
$$

According to Eq. (17), an increase in the markup rate increases the unemployment rate. We also obtain the endogenous employment rate of immigrants:

$$
\epsilon_{t}^{I M^{*}}=\frac{1}{1+u^{E^{*}}}=\mu^{-\frac{1}{\delta}} .
$$

\subsection{The government}

The government endogenously imposes a common income tax, $\tau_{t}^{E}$, on native and immigrant workers and on unemployment to finance unemployment benefits, $b_{t}^{X}$, which we set at

$$
\begin{gathered}
b_{t}^{N}=\varphi w_{t}^{F}, \\
b_{t}^{I M}=\varphi \mathrm{P} w_{t}^{F},
\end{gathered}
$$

where $\varphi$ is the replacement rate $(\varphi \in(0,1)) .{ }^{12}$ Note that the unemployment benefits differ between natives and immigrants, which implies that unemployment benefits are proportional to the taxes they pay for unemployment benefits. The budget constraint on income tax becomes

$$
\begin{gathered}
\tau_{t}^{E}\left(w_{t}^{L} E_{t}^{N}+\mathrm{P} w_{t}^{L} E_{t}^{I M}+w_{t}^{e d u} H_{t}^{N}+b_{t}^{N} U n_{t}^{N}+b_{t}^{I M} U n_{t}^{I M}\right) \\
=b_{t}^{N} U n_{t}^{N}+b_{t}^{I M} U n_{t}^{I M},
\end{gathered}
$$

where $w_{t}^{e d u}$ is the wage rate of educators.

Workers in the consumption sector face the expected income $\left(\frac{1}{1+u_{t}^{E}}\right) w_{t}^{L}+\left(\frac{u_{t}^{E}}{1+u_{t}^{E}}\right) b_{t}^{N}$ for natives and $\left(\frac{1}{1+u_{t}^{E}}\right) \mathrm{P} w_{t}^{L}+\left(\frac{u_{t}^{E}}{1+u_{t}^{E}}\right) b_{t}^{I M}$ for immigrants. Using Eq. (18), the expected income is

\footnotetext{
11 Note that the common unemployment rate in the consumption sector becomes $\frac{\mu^{\frac{1}{\delta}}-1}{\mu^{\frac{1}{\delta}}}$, which we calculate using the relation $\frac{U n_{t}^{X}}{E_{t}^{X}+U n_{t}^{X}}=\frac{u_{t}^{E} E_{t}^{X}}{E_{t}^{X}+u_{t}^{E} E_{t}^{X}}=\frac{u_{t}^{E}}{1+u_{t}^{E}}$. Additionally, an increase in $\mu$ raises the unemployment rate because we have $\frac{d}{d \mu}\left(\frac{\mu^{\frac{1}{\delta}}-1}{\mu^{\frac{1}{\delta}}}\right)=\frac{1}{\delta \mu^{\left(1+\frac{1}{\delta}\right)}}>0$.

12 It may be strange that the government imposes income tax on unemployment benefits. However, this assumption simplifies the calculations. In a sense, the income tax on unemployment benefits simply implies a decrease in the benefit level.
} 


$$
\begin{gathered}
\operatorname{In}_{t}^{N_{W}}=\eta^{*} w_{t}^{L}, \\
\operatorname{In}_{t}^{I M}=\eta^{*} \mathrm{P} w_{t}^{L},
\end{gathered}
$$

where $\eta^{*} \equiv\left(\frac{1}{1+u^{E^{*}}}\right)\left(1+\frac{\varphi}{\mu} u^{E^{*}}\right)$. Some calculation leads to $\eta^{*}<1$.

The government also collects education expenses per child, $z_{t}$, to finance the wages of educators, $w_{t}^{e d u}$, which is the same as the expected income in the consumption sector:

$$
w_{t}^{e d u}=\eta^{*} w_{t}^{L} .
$$

The budget constraint for education expenses is

$$
z_{t}\left(n_{t}^{N} N_{t}^{N}+n_{t}^{I M} N_{t}^{I M}\right)=w_{t}^{e d u} H_{t}
$$

The deterministic wage of the educator is less than that of an employed worker in the consumption sector because $\eta^{*}<1$. The income of educators, $\operatorname{In}_{t}^{N_{H}}$, is equal to the expected income in the consumption sector: $\operatorname{In}_{t}^{N_{H}}=I n_{t}^{N_{W}}=I n_{t}^{N}$, where $\operatorname{In} n_{t}^{N}$ is the native common income. We also obtain the relation $\operatorname{In}_{t}^{I M}=\mathrm{P} I n_{t}^{N}$.

\subsection{Consumption utility}

Individuals live in three periods (childhood, the working period, and retirement) and obtain utility from consumption in the latter two periods and the number of children. In the childhood period, they spend the entire time on schooling but also consume goods, which implies that their behavior in the childhood period does not affect utility. During the working period, they work when employed in the consumption or education sectors or are unemployed in the consumption sector. Thus, they obtain wages or unemployment benefits. During the old-age period, they consume their savings.

The utility function is

$$
U_{t}^{X}=\alpha \ln c_{t}^{X}+\beta \ln d_{t+1}^{X}+\gamma \ln n_{t}^{X},
$$

where $\alpha+\beta+\gamma=1$ and $X=N$ or IM. The expected budget constraints for native or immigrant individuals are, respectively,

$$
\begin{gathered}
c_{t}^{X}+z_{t}^{E} n_{t}^{X}+s_{t}^{X}=\left(1-\tau_{t}^{E}\right) I_{t}^{X}, \\
d_{t+1}^{X}=\left(1+r_{t+1}\right) s_{t}^{X} .
\end{gathered}
$$

Individuals choose the optimal consumption, savings, and number of children in the working period to maximize their utility. Some calculations lead to the following optimal solutions: 


$$
\begin{gathered}
s_{t}^{X}=\beta\left(1-\tau_{t}^{E}\right) \operatorname{In}_{t}^{X}, \\
n_{t}^{X}=\frac{\gamma}{z_{t}}\left(1-\tau_{t}^{E}\right) \operatorname{In}_{t}^{X}, \\
c_{t}^{X}=\alpha\left(1-\tau_{t}^{E}\right) \operatorname{In}_{t}^{X}, \\
d_{t+1}^{X}=\left(1+r_{t+1}\right) \beta\left(1-\tau_{t}^{E}\right) \operatorname{In}_{t}^{X} .
\end{gathered}
$$

Thus, we have the following relationships in the optimal solutions for natives and immigrants: $s_{t}^{I M}=\mathrm{P} s_{t}^{N}, n_{t}^{I M}=\mathrm{P} n_{t}^{N}, c_{t}^{I M}=\mathrm{P} c_{t}^{N}$ and $d_{t}^{I M}=\mathrm{P} d_{t}^{N}$.

\section{Welfare analysis for the native population}

By substituting Eqs. (6), (7), (9), (18), and (21) into Eq. (19), we obtain the following relationship between the disposable income rate and the employment rate:

$$
1-\tau_{t}^{E}=\frac{(1+\lambda \mathrm{P}) \eta^{*}-\left(\epsilon_{t}^{N}+\lambda \mathrm{P}_{t}^{I M^{*}}\right) \frac{\varphi}{\mu} u^{E^{*}}}{(1-\lambda \mathrm{P}) \eta^{*}} .
$$

By substituting Eqs. (2), (3), (7), and (21) and the relationship $n_{t}^{I M}=\mathrm{P} n_{t}^{N}$ into Eq. (22), we obtain the endogenously derived education expense:

$$
z_{t}^{E^{*}}=\left(\frac{1+q \lambda \mathrm{P}}{1+\lambda \mathrm{P}}\right) h^{N} \eta^{*} w_{t}^{L} .
$$

We can also obtain the endogenously derived employment rate

$$
\epsilon_{t}^{N^{*}}=\frac{(1-\gamma) \eta^{*}-\gamma \lambda \mathrm{P}_{t}^{I M^{*}}}{1+(1-\gamma) \frac{\varphi}{\mu} u^{E^{*}}}
$$

by substituting Eqs. (25) - (27) into Eq. (10). Finally, we obtain the endogenously derived common disposable income rate and the optimal number of children for natives

$$
\begin{gathered}
1-\tau_{t}^{E^{*}}=\frac{1}{1+(1-\gamma) \frac{\varphi}{\mu} u^{E^{*}}}, \\
n_{t}^{N^{*}}=\frac{\gamma(1+\lambda \mathrm{P})}{(1+q \lambda \mathrm{P})\left(1+(1-\gamma) \frac{\varphi}{\mu} u^{E^{*}}\right)}
\end{gathered}
$$


by substituting Eq. (28) into Eqs. (25) and (26).

Some calculations lead to the endogenous optimal solutions using Eqs. (20), (25), (29), and (30). We can also obtain the endogenous wage rate and interest rate in period $t$ when there are some unemployed workers: ${ }^{13}$

$$
\begin{aligned}
& w_{t}^{L}=(1-\delta)\left(k_{t}^{N}\right)^{\delta}\left(\frac{(1-\gamma)(1+\lambda \mathrm{P}) \eta^{*}}{\left(1+(1-\gamma) \frac{\varphi}{\mu} u^{E^{*}}\right)}\right)^{-\delta}, \\
& 1+r_{t}^{L}=\delta\left(k_{t}^{N}\right)^{\delta-1}\left(\frac{(1-\gamma)(1+\lambda \mathrm{P}) \eta^{*}}{\left(1+(1-\gamma) \frac{\varphi}{\mu} u^{E^{*}}\right)}\right)^{1-\delta}
\end{aligned}
$$

In period $t+1$, the number of $t+1^{\text {th }}$ generation natives is $N_{t+1}=n_{t}^{N^{*}} N_{t}^{N}+n_{t}^{I M^{*}} N_{t}^{I M}$ 14. The relationship between the number of children in the native and immigrant groups is $n_{t}^{I M^{*}}=\mathrm{P} n_{t}^{N^{*}}$. Thus, the number of $t+1^{\text {th }}$ generations is $N_{t+1}=(1+\lambda \mathrm{P}) n_{t}^{N^{*}} N_{t}^{N}$. We also have the amount of capital in period $t+1$ : $K_{t+1}=(1+\lambda \mathrm{P}) s_{t}^{N^{*}} N_{t}^{N}$. The capital-labor ratio in period $t+1$ is $k_{t+1}^{T}=\frac{s_{t}^{N^{*}}}{n_{t}^{N^{*}}}$, which does not depend on whether immigration exists or not. Thus, there is no influence of immigration in period $t$ after period $t+1$.

We define the social welfare function of the native population as

$$
W_{t}^{N}=\sigma^{t-1} \sum_{t=0}^{\infty} U_{t-1}^{N}
$$

where $\sigma \in(0,1)$ is the discount rate between generations. We define the native social welfare function as the discounted aggregated utility of the native population per capita.

By substituting the endogenous optimal solutions and Eqs. (31) and (32) into (23), we obtain the indirect utility function for natives:

$$
U_{t}^{N}=\ln \left(\left(1-\tau_{t}^{E^{*}}\right) \operatorname{In}_{t}^{N}\right)+\beta \ln \left(1+r_{t+1}^{L}\right)-\gamma \ln \left(z_{t}^{E^{*}}\right)+D,
$$

where $D=\alpha \ln (\alpha)+\beta \ln (\beta)+\gamma \alpha \ln (\gamma)$.

By differentiating Eq. (33) with respect to $\lambda$, we obtain

$$
\frac{d W_{t}^{N}}{d \lambda}=\frac{\beta}{\sigma} \frac{(1-\delta) \mathrm{P}}{(1+\lambda \mathrm{P})}-\frac{\delta \mathrm{P}}{(1+\lambda \mathrm{P})}-\gamma\left(\frac{(q-1) \mathrm{P}}{(1+q \lambda \mathrm{P})(1+\lambda \mathrm{P})}-\frac{\boldsymbol{\delta P}}{(1+\lambda \mathrm{P})}\right)
$$

There are three factors influencing the welfare of the natives. The first term in Eq. (35) is the discounted value of an increase in the utility of the retired generation through the rate of return. The second term in Eq. (35) is the increase in the

\footnotetext{
13 We easily obtain $\frac{\partial w_{t}^{L}}{\partial \lambda}<0$ and $\frac{\partial\left(1+r_{t}^{L}\right)}{\partial \lambda}>0$ with some calculations, which are intuitively the same results as in the literature.

14 We assume that the children of immigrants can have productivity similar to native children and that they are assimilated in the host country owing to the additional educators.
} 
Table 1 Exogenous parameters and the endogenous value of $q^{*}$

\begin{tabular}{lllllll}
\hline & $\sigma$ & $\alpha$ & $\beta$ & $\gamma$ & $\delta$ & $q^{*}$ \\
\hline Case A & 0.95 & 0.3 & 0.25 & 0.45 & $1 / 3$ & -0.018 \\
Case B & 0.8 & 0.3 & 0.25 & 0.45 & $1 / 3$ & 0.056 \\
Case C & 0.95 & 0.5 & 0.25 & 0.25 & $1 / 3$ & -0.298 \\
Case D & 0.95 & 0.3 & 0.4 & 0.3 & $1 / 3$ & 0.158 \\
Case E & 0.95 & 0.3 & 0.25 & 0.45 & $1 / 4$ & 0.133 \\
\hline
\end{tabular}

Note $\sigma$ is the discount rate between generation. $\alpha, \beta$, and $\gamma$ are the preferences for consumption in the working period, consumption in the retired period, and number of children, respectively. $\delta$ is the capital share. $q^{*}$ is the endogenously calculated upper bound of the necessary number of educators that can improve native welfare.

utility of the working generation through the wage rate. The last term in Eq. (35) is a very important factor that affects decisions about the number of children in the educational sector, including an increase in the burden caused by an increase in the required number of educators and a decrease in the burden caused by a decrease in the wage rate per capita of the necessary educators.

Furthermore, evaluating Eq. (35) with $\lambda=0$, we obtain

$$
\left.\frac{d W_{t}^{N}}{d \lambda}\right|_{\lambda=0}=\mathrm{P}\left[\left(\frac{\beta}{\sigma}+\gamma\right)(1-\delta)-(1-\gamma) \delta-\gamma(q-1)\right]
$$

Thus, we have the following proposition:

Proposition Immigration improves native welfare when the necessary number of educators is sufficiently small.

Proof: $\left.\frac{d W_{t}^{N}}{d \lambda}\right|_{\lambda=0} \geq 0$ if

$$
q-1 \leq \frac{1}{\gamma}\left(\frac{\beta}{\sigma}(1-\delta)-(1-\gamma) \delta\right) .
$$

We should pay attention to the condition in the Proposition, which does not depend on the value of the productivity of the admitted immigrants, $\mathrm{P}$, but depends only on the value of the necessary number of educators, $(q-1)$, which refers to the relative increment in the necessary number of educators as a result of immigration.

Admitting immigrants directly increases the labor force. As Friedberg and Hunt (1995) and Edo (2019) explain, an increase in the labor force raises the rate of return from savings but decreases the wage rate. The productivity of immigrants determines the increase in the labor force. Thus, the absolute changes in the return rate from savings and the wage rate depend on the value of the productivity of immigrants. 
Admitting immigrants indirectly changes education costs because immigrants need a relatively higher number of educators. This change can be either negative or positive. The increment in the necessary number of educators generally raises the cost of education for natives because they, as well as immigrants, finance the wages of educators (negative effects). However, an increase in the labor force caused by immigration decreases the wage rate of educators to be financed by education costs; natives must also pay for their own children (positive effects). Thus, changes in education costs can be negative or positive.

Consequently, whether the welfare of natives will increase depends mainly on the increment in the necessary number of educators caused by immigration, which implies that the most important factor improving the welfare of the native population becomes the increment in the necessary number of educators when immigrants are admitted. We can discuss the implications because this model considers the educational sector under an endogenous fertility model.

We consider a numerical example by considering the following exogenous parameters (see Table 1), where we define the right-hand side of the condition of the Proposition, $\frac{1}{\gamma}\left(\frac{\beta}{\sigma}(1-\delta)-(1-\gamma) \delta\right)$ as $q^{*}$. According to Table 1 , the value of $q^{*}$ can be negative or positive. Thus, the permissible range of increments in the necessary number of educators can be very small. However, improving the welfare of the native population is possible when the discount rate between generations is sufficiently low (Case B), when the preference for consumption is sufficiently high (Case D), and the distribution factor for capital is sufficiently low.

According to the OECD (2020), the ratio of students to teaching staff in primary (lower secondary) educational institutions in Japan is 16.2 (13.0), compared to the OECD average of 14.6 (13.0). Thus, while the ratio of students to teaching staff in primary educational institutions in Japan is slightly higher than the OECD average, the ratio in Japan's lower secondary educational institutions is the same as the OECD average. The value of $h^{N}$ in primary (lower secondary) educational institutions in Japan is $0.06(0.08)$.

The Ministry of Education, Culture, Sports, Science and Technology decided that the minimum number of teachers providing support as Japanese language teaching assistants will increase to one teacher per 18 children by 2026 (Nikkei 2020). The targeted value of $h^{I M}$ in primary (lower secondary) educational institutions will thus become $0.12(0.13)$, which we calculate by adding the $h^{N}$ of $0.06(0.08)$ to the $h^{I M}$ of $0.06(0.06)$ using the scheduled ratio of one to 18 as the value of $h^{I M}$ in primary (lower secondary) educational institutions. ${ }^{15}$ These values lead to an estimated $q-1$ in primary (lower secondary) educational institutions of $0.90(0.72)$, which is greater than any value of $q^{*}$ in Table 1 . Thus, the scheduled improvement of support for immigrant children in Japan may unfortunately be an extra burden according to the numerical analysis in this model.

\footnotetext{
15 These data are rounded off to the second decimal place. Thus, the total targeted value becomes less than the sum of $h^{N}$ and $h^{I M}$.
} 
However, this analysis uses the necessary number of additional instructors required to support immigrant children receiving education in Japan. We should consider the real financial burden of hiring the necessary number of these additional instructors that immigrant children would need. The annual income of language support instructors for foreign children in Aichi Prefecture, where the number of foreign students in need of instruction is the highest among all prefectures, was 3,277.7 thousand yen in 2019 (Ministry of Education, Culture, Sports, Science and Technology 2019) according to direct interviews with civil servants employed by the Aichi Prefecture government in 2020. Meanwhile, the annual income of workers in the education and learning support sector was 5,815.7 thousand yen in 2020 (Ministry of Health, Labour and Welfare 2021). Thus, the real value of $h^{I M}$ in primary (lower secondary) educational institutions, including the additional burden, is 0.09 (0.11). These values lead to an estimated $q-1$ in the primary (lower secondary) educational institutions in Aichi of $0.51(0.41)$, which is greater than any value of $q^{*}$ in Table 1. Thus, improving support for immigrant children in Japan may unfortunately be an extra burden according to the numerical analysis in this model.

We also have the following two lemmas:

Lemma 1 The unemployment rate of the immigrant population is always lower than that of the native population.

Proof We have $\frac{U n_{t}^{N^{*}}}{N_{t}^{N}}=u_{t}^{E^{*}} \epsilon_{t}^{N^{*}}, \frac{U n_{t}^{I M^{*}}}{N_{t}^{I M}}=u_{t}^{E^{*}} \epsilon_{t}^{I M^{*}}$ and Eq. (11). Because $\frac{1}{1-\left(n_{t}^{N}+\lambda q n_{t}^{I M}\right) h^{N}}$ is less than $1, \frac{U n_{t}^{N^{*}}}{N_{t}^{N}}>\frac{U n_{t}^{I M^{*}}}{N_{t}^{I M}}$.

Lemma 2 Immigration lowers the employment rate in the consumption sector.

Proof By differentiating Eq. (28) with respect to $\lambda$ and evaluating it with $\lambda=0$, we obtain $\left.\epsilon_{t}^{N^{*}}\right|_{\lambda=0}=\frac{(1-\gamma) \eta_{t}^{*}}{1+(1-\gamma) \frac{\varphi}{\mu} u_{t}^{E^{*}}}$, which is higher than $\epsilon_{t}^{N^{*}}=\frac{(1-\gamma) \eta_{t}^{*}-\left(\frac{1}{1+u_{t}^{E^{*}}}\right)}{1+(1-\gamma) \frac{\varphi^{\varphi}}{\mu} E_{t}^{E^{*}}}$.

Thus, the number of employees increases if immigration exists.

Lemma 2 implies that immigration increases the employment of the native population, which is calculated only after considering the educational sector. This lemma shows the constructional theory of phenomena estimated by Basten (2019), Furlanetto and Robstad (2019), and Esposito et al. (2020).

\section{Discussion of assumptions about immigrant children}

To determine the clear structural effects of immigration through the education sector, we assume that the children of immigrants receiving additional educational support will assimilate into the native population. However, as the OECD's (2019) 
PISA 2018 results show, the scores of immigrant children are in fact lower than those of native children, though the former receive some additional support from educators in some host countries. This fact implies that we should also analyze the effects of immigration on the assumption that the children of immigrants cannot overcome certain disadvantages despite receiving additional educational support. In this case, the disadvantages of immigrant children imply a decrease in the labor supply of the next generation, which decreases the rate of return from savings. Thus, the disadvantages of immigrant children will basically decrease the permissible range of increment in the native population's welfare. Yet, how the permissible range of the increment in the native population's welfare decreases remains to be solved.

This model is simple in that it treats the children of immigrants as native children. Some of the effects of being an immigrant child decrease as they continue to live in the host country. Nevertheless, future models should also pay attention to the persistent effects of being a descendant of immigrants since we do not consider such effects in the present model.

\section{Concluding remarks}

We examine the effects of immigration on the burden of providing schooling to native and immigrant children. Though it might sound paradoxical, the model shows that immigration might improve the welfare of the native population when the number of educators immigrant children need is sufficiently low. Moreover, immigration improves the employment rate of native immigrants.

We identify the structural factor estimated as the positive effects of immigration in Basten and Siegenthale (2019), Furlanetto and Robstad (2019), and Esposito et al. (2020) — namely, the structural positive effects of admitting international immigrants on citizen employment rates-only after considering the educational sector. Even if immigration might decrease the wages of the native population and change the financial burden of the native population through the education sector, there is a possibility of welfare improvement when the necessary number of educators for immigrants is sufficiently low. This result can only be obtained after considering the education sector, which is indirectly affected by immigration.

This possibility, as we describe here, can encourage the native population to be receptive to immigration even in the model without a pension system, which could cause some friction, especially for the succeeding working generation. However, there is, unfortunately, no possibility of native welfare improvement using the scheduled increases in educational support to immigrant children in Japan. A major reason for this is that we do not consider the pension system or the nursing and welfare service systems in our model, even though advanced host countries employ immigrants mainly because these systems would otherwise almost collapse as a result of population aging. Thus, we would like to consider the effects of immigration in a future model that includes the structural labor 
movement from the consumption sector to the educational sector, as well as pension or nursing and welfare service systems.

Moreover, this model does not consider educational decisions, which are related to human capital accumulation. Essentially, natives will make educational decisions in response to immigration (Casarico and Devillanova 2003; McHenry 2015; Brunello et al. 2020). As Casarico and Devillanova (2003) and McHenry (2015) explain, in terms of the endogenous educational responses of the native population, immigration may increase human capital accumulation in the native population because of the decreasing wage rate caused by immigration. Notably, Casarico and Devillanova (2003) demonstrate the possibility that natives, forced to accumulate human capital, would be worse off. Furthermore, Brunello et al. (2020) show that admitting unskilled immigrants raises both the share of young natives with a college education or those enrolled in college and the share of loweducated natives who have completed compulsory education but are not engaged in further education-a polarizing mechanism. This polarizing mechanism makes the effects of admitting unskilled immigrants on the wage gap between skilled and unskilled workers more persistent, though the expectation is that this gap will be short lived because of capital inflows.

The papers mentioned above imply that immigration has two opposing effects on educational support. While admitting unskilled immigration will force more unskilled natives to accumulate human capital — which increases the need for educational support for those who would like to accumulate human capital-it decreases the need for educational support because more unskilled natives will continue to accumulate human capital. Thus, adding the educational decision to the model would have unclear effects on the need for educational support. Whether admitting unskilled immigrants will increase or decrease the need for educational support to accumulate human capital remains to be further investigated.

Acknowledgements We would like to thank the seminar participants at the second meeting of the Nanzan Association in 2020 and the meeting of the Kamishiro project at Kanto-Gakuin University, and an anonymous reviewer for their helpful comments. This study was funded by the Ministry of Education, Culture, Sports, Science and Technology of Japan (JSPS grant number: KAKENHI 19K01636) and the Nitto Foundation.

Author contributions All authors contributed to the study conception and design. Material preparation, data collection, and analysis were performed by Masatoshi Jinno and Massaya Yasuoka. The first draft of the manuscript was written by Masatoshi Jinno, and all authors commented on the various drafts. All authors read and approved the final manuscript.

Funding This study was funded by the Ministry of Education, Culture, Sports, Science and Technology of Japan (JSPS grant number: KAKENHI 19K01636) and the Nitto Foundation.

\section{Declarations}

Conflict of interest The authors have no conflicts of interest to declare that are relevant to the content of this article. 
Open Access This article is licensed under a Creative Commons Attribution 4.0 International License, which permits use, sharing, adaptation, distribution and reproduction in any medium or format, as long as you give appropriate credit to the original author(s) and the source, provide a link to the Creative Commons licence, and indicate if changes were made. The images or other third party material in this article are included in the article's Creative Commons licence, unless indicated otherwise in a credit line to the material. If material is not included in the article's Creative Commons licence and your intended use is not permitted by statutory regulation or exceeds the permitted use, you will need to obtain permission directly from the copyright holder. To view a copy of this licence, visit http://creativecommons.org/licen ses/by/4.0/.

\section{References}

Albornoz F, Berlinski S, Cabrales A (2018a) Motivation, resources, and the organization of the school system. J Eur Econ Assoc 16(1):199-231. https://doi.org/10.1093/jeea/jvx001

Albornoz F, Cabrales A, Calvo P, Hauk E (2018b) Immigrant children's school performance and immigration costs: evidence from Spain. Econ Lett 170:27-30. https://doi.org/10.1016/j.econlet.2018.05.015

Albornoz F, Cabrales A, Hauk E (2018c) Immigration and the school system. Econ Theory 65(4):855-890. https://doi.org/10.1007/s00199-017-1041-4

Basten C, Siegenthaler M (2019) Do immigrants take or create residents' jobs? evidence from free movement of workers in Switzerland. Scand J Econ 121(3):994-1019. https://doi.org/10.1111/sjoe.12293

Borjas GJ (2003) The labor demand curve is downward sloping: reexamining the impact of immigration on the labor market. Q J Econ 118(4):1335-1374. https://doi.org/10.1162/003355303322552810

Breunig R, Deutscher N, To HT (2017) The relationship between immigration to Australia and the labour market outcomes of Australian-born workers. Econ Rec 93(301):255-276. https://doi.org/10.1111/ $1475-4932.12328$

Brunello G, Lodigiani E, Rocco L (2020) Does low skilled immigration increase the education of natives? Evid Italian Prov Labour Econ 63:101794. https://doi.org/10.1016/j.labeco.2019.101794

Card D (2001) Immigrant inflows, native outflows and the local labor market impact of higher immigration. J Labor Econ 19:22-64. https://doi.org/10.1086/209979

Casarico A, Devillanova C (2003) Social security and migration with endogenous skill upgrading. J Public Econ 87(3-4):773-797. https://doi.org/10.1016/S0047-2727(01)00181-5

Deputy Director-General, Elementary and Secondary Education Bureau. 2021 Kotogakko Kyoiku no Genjyo ni tsuite (in Japanese) https://www.mext.go.jp/a_menu/shotou/kaikaku/20210315-mxt_kouhou02-1. pdf. Accessed 16 March 2021

Dustmann C, Schönberg U, Stuhler J (2017) Labor supply shocks, native wages, and the adjustment of local employment. Q J Econ 132(1):435-483. https://doi.org/10.1093/qje/qjw032

Edo A (2019) The impact of immigration on the labor market. J Econ Surv 33(3):922-948. https://doi.org/10. 1111/joes. 12300

Esposito P, Collignon S, Scicchitano S (2020) The effect of immigration and unemployment in Europe: does the core-periphery dualism matter? Econ Model 84:249-258. https://doi.org/10.1016/j.econmod.2019. 04.014

Friedberg RM, Hunt J (1995) The impact of immigrants on host country wages, employment and growth. J Econ Perspect 9(2):23-44. https://doi.org/10.1257/jep.9.2.23

Furlanetto F, Robstad Ø (2019) Immigration and the macroeconomy: some new empirical evidence. Rev Econ Dyn 34:1-19. https://doi.org/10.1016/j.red.2019.02.006

Hunt $\mathbf{J}$ (2017) The impact of immigration on the educational attainment of natives. J Hum Resour 52(4):1060-1118. https://doi.org/10.3368/jhr.52.4.0115-6913R1

International Organization for Migration (IOM) (2019) World migration report 2020 The United Nations, Switzerland https://doi.org/10.18356/b1710e30-en

Jackson O (2015) Does immigration crowd natives into or out of higher education? Working papers, No. 15-18, Federal Reserve Bank of Boston, Bostons https://doi.org/10.2139/ssrn.2329298

Jinno M (2011) Assimilation, immigration, and the welfare state. FinanzArchiv 67(1):46-63. https://doi.org/ $10.1628 / 001522111$ X574182

Jinno M (2013) The impact of immigration under the defined-benefit pension system: an analysis incorporating assimilation costs. Demogr Res 28:613-636

Kemnitz A (2003) Immigration, unemployment and pensions. Scand J Econ 105(1):31-47. https://doi.org/10. $1111 / 1467-9442.00003$ 
Kojima Y (2016) Gaikokujin no syugaku to husyugaku (in Japanese). Osaka University Press, Osaka

Mavisakalyan A (2011) Immigration, public education spending, and private schooling. South Econ J 78(2):397-423. https://doi.org/10.4284/0038-4038-78.2.397

McHenry P (2015) Immigration and the human capital of natives. J Hum Resour 50(1):34-71. https://doi. org/10.1353/jhr.2015.0002

Ministry of Health, Labour and Welfare (2021) Basic survey on wage structure (in Japanese) https://www. mhlw.go.jp/toukei/itiran/roudou/chingin/kouzou/z2020/index.html. Accessed 21 July 2021

Ministry of Education, Culture, Sports, Science and Technology (2019) Survey on the acceptance of foreign students in need of Japanese (in Japanese) https:/www.mext.go.jp/b_menu/houdou/31/09/1421569_ 00001.htm. Accessed 25 July 2021

Ministry of Justice (2020) Statistics on foreign nationals residing in Japan (in Japanese). http://www.moj.go. jp/isa/policies/coexistance/nyuukokukanri01_00140.html. Accessed 16 March 2021

Muysken JJ, Vallizadeh E, Ziesemer T (2015) Migration, unemployment, and skill downgrading. Scand J Econ 117(2):403-451. https://doi.org/10.1111/sjoe.12104

Nikkei (2020) Japanese lessen becomes formal course (translated from Japanese). Nikkei Nov 26. https:// www.nikkei.com/article/DGXMZO66638170V21C20A1CR8000. Accessed 16 March 2021

OECD (2019) PISA 2018 results (volume II): Where all students can succeed. PISA, OECD Publishing, Paris. https://doi.org/10.1787/b5fd1b8f-en

OECD (2020) Education at a glance 2020: What is the student-teacher ratio and how big are classes? OECD Publishing, Paris. https://doi.org/10.1787/69096873-en

Razin A, Sadka E (1999) Migration and pension with international capital mobility. J Public Econ 74(1):141150. https://doi.org/10.1016/S0047-2727(99)00038-9

Razin A, Sadka E (2000) Unskilled migration: a burden or a boon for the welfare state? Scand J Econ 102(3):463-479. https://doi.org/10.1111/1467-9442.00210

Speciale B (2012) Does immigration affect public education expenditures? Quasi Exp Evid J Public Econ 96(9-10):773-783. https://doi.org/10.1016/j.jpubeco.2012.04.004

United Nations Department of Economic and Social Affairs, Population Division (2019) International migrant stock 2019. United Nations database, POP/DB/MIG/Stock/Rev.2019. https://www.un.org/en/ development/desa/population/migration/data/estimates2/docs/MigrationStockDocumentation_2019. pdf. Accessed 16 March 2021

Publisher's Note Springer Nature remains neutral with regard to jurisdictional claims in published maps and institutional affiliations. 